\title{
Cambios en la concepción y en los usos de la ruralidad: del antropocentrismo productivista al ecocentrismo naturalista
}

\section{Changes in the conception and the uses of rurality: from productivist antropocentrism to naturalist econcentrism}

\author{
Francisco Entrena DURÁN*, José Luis VILLANUEVA PÉREZ
}

\begin{abstract}
RESUMEN
La ruralidad es concebida aquí como una construcción social, es decir, como un producto (no intencional ni previsto, en la mayoría de los casos) de la acción social humana. Los usos y la concepción de la ruralidad, que varían en función del tiempo y la situación social en que se lleva a cabo su construcción social, han pasado, durante la segunda mitad del siglo XX, de desarrollarse en un contexto que los autores califican como antropocentrismo productivista a hacerlo en otro de creciente preponderancia de lo que ellos tipifican como ecocentrismo naturalista. Esto ha implicado cambios en la manera de entender el papel de la agricultura y la relación de ésta con la naturaleza, a la vez que ha dado lugar a una nueva concepción de la ruralidad. Este artículo, que presta una especial atención a la evolución sociohistórica de la imagen y los usos de la ruralidad en España, concluye con un análisis de las posiciones y las actitudes manifestadas actualmente en este país con respecto a la nueva manera de entender la ruralidad y a la creciente incidencia en los efectos medioambientales de la agricultura que ello conlleva.
\end{abstract}

\begin{abstract}
Rurality, in this paper, is considered as a social construction, that is to say, as a product (in most cases neither intentional nor anticipated) of the human social action. The uses and the conception of rurality, which depend on the specific time and social situation in which its social construction is performed, have changed its way of development since the second half of the twentieth century, from a context of a productivist antropocentrism to a growing prevalence typified as naturalist econcentrism, according to the terms used by the authors. This transformation has generated some changes in the understanding of agriculture and how this is related to nature, creating a new rurality conception. This paper, which focuses its attention on the socio-historic evolution of the image and the uses of the Spanish rurality, concludes with an analysis of the postures and the commonest attitudes shown in this country. This are related to the new rurality understanding and the growing incidence implied in the environmental effects caused by the agriculture.
\end{abstract}

* Departamento de Sociología de la Universidad de Granada (España). Página Web personal: http://www.ugr.es/ fentrena/E-mail: fentrena@goliat.ugr.es 


\section{De la agricultura de subsistencia tradicional al antropocentrismo productivista}

La ruralidad es el resultado de una construcción social. Con ello no queremos decir que la ruralidad sea una especie de constructo o invención de la sociedad humana, sino que la misma constituye una situación social cuya construcción o conformación es un efecto (no intencional ni previsto, en la mayoría de los casos) resultante a partir de procesos de acción social humana, entendida aquí esta acción en un sentido amplio que engloba lo socioeconómico, lo político-institucional y lo simbólico-cultural (Entrena, 1998). Los usos y la concepción de la ruralidad cambian en función del contexto social y temporal en el que se lleva a cabo su construcción social. En las páginas siguientes, veremos como, durante la segunda mitad del siglo XX, los usos y la concepción de la ruralidad han pasado de desarrollarse en un contexto que calificamos como antropocentrismo productivista a hacerlo en otro de creciente preponderancia de lo que tipificamos como ecocentrismo naturalista. Esto ha implicado cambios en la concepción de la agricultura y del papel de ésta, y, como consecuencia, modificaciones en las relaciones entre la sociedad y la naturaleza que en el ámbito rural conlleva la actividad agraria.

A lo largo de la evolución de la humanidad, el difícil e inestable equilibrio de las relaciones entre el hombre y la naturaleza se ha encontrado amenazado desde ambas orillas: por un lado, la historia refiere casos de grupos humanos que se extinguieron al sobrepasar las formas permisibles y tolerables de la explotación de su entorno natural, así como también es posible encontrar zonas devastadas del planeta donde, como resultado de la acción del hombre, es inviable cualquier mínima actividad productiva. La agricultura, en tanto que práctica productiva a través de la cual el hombre ha influido tradicionalmente en su entorno natural, puede ser considerada como una manipulación de los "ecosistemas naturales" con el propósito de convertirlos en "agroecosistemas". Partiendo de esta premisa, la producción agraria sería el resultado de las presiones técnicas y socioeconómicas que el hombre lleva a cabo sobre el medio natural.

En el contexto de la economía de subsistencia preponderante en las tradicionales sociedades agrarias existía un alto grado (en comparación con lo que sucede en las formas de agricultura moderna típicas de sociedades industriales avanzadas) de adaptación y sometimiento del hombre a los cambios experimentados por la naturaleza, de tal forma que la renovabilidad de los recursos naturales y la consiguiente preservación de los ecosistemas estaban garantizadas por la propia dinámica interna de los ciclos de la naturaleza. Sin duda, esta situación contribuía a favorecer, entre los moradores del agro tradicional, el desarrollo de una cierta percepción de los problemas medioambientales de su entorno. Así, están en lo cierto aquellos autores que, como es el caso de Brenton (1994), sostienen que en las sociedades tradicionales agrarias se han planteado algunos de tales problemas, como, por ejemplo, los derivados de la existencia de una excesiva presión demográfica en relación con la capacidad productiva que tiene el medio rural. Lo cierto es que, sin que ello pueda ser considerado como una conciencia ecológica en el sentido en que ésta es entendida actualmente, la generalidad de las sociedades tradicionales agrarias suele manifestar un sentido (más o menos acentuado, según los casos) de su relación de vinculación con su entorno medioambiental natural. En gran medida, esto se debe a que, para dichas sociedades, tal entorno es, a la vez, su espacio para la producción agraria y el lugar en el que viven y consumen dicha producción, por lo que su interés en la preservación del mismo estriba, sobre todo, en que en ello les va su propia supervivencia como sociedades y como colectivos poblacionales. Pero, también, este sentido de vinculación con el entorno medioambiental natural está motivado por las considerables carencias de conocimientos, de medios y de técnicas que tienen las sociedades agrarias tradicionales. Éstas, si se compara su situación a este respecto con la de las sociedades industriales modernas avanzadas, manifiestan notables limitaciones para enfrentarse con eficacia a 
los retos y problemas que les plantea su entorno natural. Limitaciones que propician una necesidad de acomodarse a dicho entorno, una especie de adecuación a las exigencias del mismo basada en una sensación general de impotencia para dominarlo y controlarlo que llevaba a los seres humanos a asumir la idea de que estaban sometidos a las leyes de la naturaleza.

De esta forma, la actividad social, productiva y cultural de la población rural tradicional acaba por adaptarse a los ritmos de la naturaleza, a sus ciclos o estaciones anuales, lo que, a su vez, da lugar a que dicha población suela participar de una visión circular y quietista del tiempo, de la vida y de la marcha de los fenómenos cósmicos, cuya estabilidad se ve, por ejemplo, constatada mediante la observación de las transformaciones cíclicas experimentadas por el medio natural en el transcurso de las estaciones del año, o, desde otro punto de vista, a través de la experiencia cotidiana de la secuencia, también cíclica, de los ritmos de nacimiento, vida, muerte y regeneración de la totalidad de la materia viviente (Entrena, 1992, p. 154-155).

Como es sabido, el paulatino afianzamiento de la sociedad industrial moderna conllevó notables avances técnicos y científicos que alentaron la extensión de esa idea de progreso, tan extendida en el siglo XIX, según la cual las posibilidades de crecimiento y de desarrollo, que entonces se suponía eran prácticamente ilimitadas, eran de tal magnitud que podía considerarse que, por fin, la humanidad se encontraba en condiciones de hacer frente, con la garantía de que iba a superarlas, a las ancestrales limitaciones técnicas y de conocimientos que habían determinado su relación con su medio natural. Esto, que en el mundo rural hizo posible el tránsito gradual de una economía agraria tradicional de subsistencia a otra de carácter industrial capitalista, tuvo lugar paralelamente al paulatino reemplazo de la idea de subordinación de los hombres a su medio natural por una nueva mentalidad, según la cual éstos pueden controlar la naturaleza y romper su tradicional relación de dependencia con respecto a ella. Se extendió, así, una conciencia antropocéntrica, que estaba en concordancia con las enormes posibilidades de actuación humana que ofrecían los avances científico-técnicos, y de la que participaba la generalidad de los clásicos del pensamiento sociológico, incluido el propio Marx. Éste, análogamente al resto de sus contemporáneos, también compartía la idea de que el hombre es el dueño absoluto del medio natural, el cual está completamente a su servicio dispuesto para ser conquistado y explotado de manera ilimitada ${ }^{\text {. }}$. Hablamos de conciencia antropocéntrica porque, de acuerdo con ella, de estar subordinada a los requerimientos de los ritmos y ciclos de la naturaleza, la humanidad pasaba a erigirse en un sujeto central del orden natural y cósmico, concebidos, sobre todo, como una realidad externa a ella, cuya voluntad y acción son decisivas en la explotación y transformación del mundo.

El antropocentrismo conllevaba el progresivo asentamiento de esa nueva forma de racionalidad que Weber (1979, p. 29) conceptuó como una racionalidad instrumental medios-fines, lo que suponía la paulatina instauración de una praxis (determinante/determinada de/por los adelantos tecnológicos que acompañaron su desarrollo) amparada en una mentalidad manipuladora de la realidad en general que, frente a las restricciones y carencias a las que se había encontrado sometida la humanidad hasta entonces, propugnaba la articulación racional de proyectos (a fin de cuentas, de medios instrumentales) encaminados a participar activamente en la regulación y modificación de la naturaleza, a romper los límites que imponía la misma para la trans-

${ }^{1}$ Aunque Marx contempló la importancia de lo que se denomina la "naturaleza" como fuente de riqueza y aunque llegó a percatarse de que el proceso productivo desarrollado por el sistema capitalista pone en peligro la "naturaleza", no llegó a superar el antropocentrismo característico de los pensadores de su tiempo. Es más, este antropocentrismo está tan arraigado en Marx que, para él, la "naturaleza" no produce por sí misma valor, sino que sólo transfiere su propio valor en el proceso de trabajo. Tal proceso, que para Marx es una de las actividades básicas del ser humano, constituye una de las bases fundamentales de ese antropocentrismo o de lo que es igual del protagonismo central que dicho autor otorga al hombre en la gestión del funcionamiento y del cambio de la "naturaleza" (Marx, 1975). 
formación del mundo y el desarrollo de las fuerzas productivas. Estaba extendida la presuposición, más o menos explícita o implícita, de que los recursos de la naturaleza eran prácticamente inagotables y de que ésta estaba ahí para ser explotada por los hombres sin ninguna restricción. Se consideraba que las posibilidades de crecimiento eran virtualmente infinitas. Todo esto estaba de acuerdo con una visión prometéica de la tarea de los actores humanos individuales y colectivos, según la cual éstos eran concebidos como artífices del funcionamiento y de la explotación de los recursos supuestamente ilimitados del planeta, como protagonistas activos del cambio y, en definitiva, "como productores del progreso", entendido "como algo que ha de alcanzarse, construirse, desarrollarse, y que requiere por tanto un esfuerzo creativo, una lucha, una búsqueda" (Sztompka, 1995, p. 54).

Esta mentalidad estaba en pleno vigor cuando, después de la Segunda Guerra Mundial, el medio rural de los países avanzados experimentó un proceso de progresiva modernización y mecanización de las tareas de labranza. La aplicación de los conocimientos científicos y técnicos entonces existentes a la agricultura se hacía orientada por la suposición y la confianza de que, por fin en su historia, los seres humanos tenían los medios para superar las ancestrales limitaciones y carencias de las tradicionales economías agrarias de subsistencia, por fin era posible aumentar e intensificar la producción hasta alcanzar unas cotas hasta entonces inimaginables; el crecimiento económico pasaba a erigirse en el principal indicador de desarrollo y de progreso. Desde la conciencia antropocéntrica que orientaba y alentaba esta visión cuantitativista y productivista (expansión de la producción frente a las carencias seculares de las economías agrarias de subsistencia del medio rural tradicional) del desarrollo, el medio agrario, como la generalidad del entorno natural, estaba ahí, como una realidad externa a los hombres, dispuesto para ser explotado sin ninguna limitación, lo único que se precisaba era poner en práctica los métodos y las técnicas de cultivo adecuadas para conseguir de él unos incrementos de la productividad y de la producción, así como unos beneficios cuya evolución se suponía tendería hacia un continuo incremento.

Bajo la orientación de estas premisas, se ponían en práctica unas nuevas formas de agricultura tecnificada que iban reemplazando a las tradicionales prácticas agrarias y que conllevaban serios peligros para la renovabilidad natural de los ecosistemas rurales, tal y como correspondía a una visión fragmentaria de los mismos, los cuales, a medida que avanzaban y se afianzaban estas nuevas formas de agricultura, tendían a dejar de ser concebidos como ámbitos en los que una población producía, vivía y consumía lo producido para pasar a ser considerados, sobre todo, como lugares destinados a la producción. En consonancia con ello, más que hacia la población rural en general, el interés de las políticas agrarias de entonces se dirigía hacia los agricultores, en tanto que productores, cuyo grado de preparación para desarrollar las tareas de cultivo y producción de alimentos se trataba de mejorar: la llamada profesionalización de este sector. En tal situación, de acuerdo con la racionalidad instrumental medios-fines que como hemos dicho antes constituye uno de los pilares básicos de legitimación y sustentación de la conciencia antropocéntrica, la eficacia en los métodos de producción y en el incremento de los rendimientos de ésta pasaban a erigirse en los objetivos centrales. Para conseguir estos objetivos, los impulsores del proceso de modernización de la agricultura concentraron sus esfuerzos fundamentalmente en favorecer la dimensión productiva del agro, lo que, como es sabido, acabó por dar lugar a una creciente degradación de la calidad de éste como medio de vida y, a la larga, también de la calidad de los productos agrarios producidos mediante el abuso de fertilizantes, de los pesticidas y de otros productos químicos usados en el cultivo.

En el caso específico de España, el proceso de modernización agraria comenzó a partir de los años cincuenta del siglo XX. Este proceso y el consiguiente afianzamiento del antropocentrismo productivista en la agricultura española tuvieron lugar en el marco del relativo aislamiento que, para nuestra situación 
los retos y problemas que les plantea su entorno natural. Limitaciones que propician una necesidad de acomodarse a dicho entorno, una especie de adecuación a las exigencias del mismo basada en una sensación general de impotencia para dominarlo y controlarlo que llevaba a los seres humanos a asumir la idea de que estaban sometidos a las leyes de la naturaleza.

De esta forma, la actividad social, productiva y cultural de la población rural tradicional acaba por adaptarse a los ritmos de la naturaleza, a sus ciclos o estaciones anuales, lo que, a su vez, da lugar a que dicha población suela participar de una visión circular y quietista del tiempo, de la vida y de la marcha de los fenómenos cósmicos, cuya estabilidad se ve, por ejemplo, constatada mediante la observación de las transformaciones cíclicas experimentadas por el medio natural en el transcurso de las estaciones del año, o, desde otro punto de vista, a través de la experiencia cotidiana de la secuencia, también cíclica, de los ritmos de nacimiento, vida, muerte y regeneración de la totalidad de la materia viviente (Entrena, 1992, p. 154-155).

Como es sabido, el paulatino afianzamiento de la sociedad industrial moderna conllevó notables avances técnicos y científicos que alentaron la extensión de esa idea de progreso, tan extendida en el siglo XIX, según la cual las posibilidades de crecimiento y de desarrollo, que entonces se suponía eran prácticamente ilimitadas, eran de tal magnitud que podía considerarse que, por fin, la humanidad se encontraba en condiciones de hacer frente, con la garantía de que iba a superarlas, a las ancestrales limitaciones técnicas y de conocimientos que habían determinado su relación con su medio natural. Esto, que en el mundo rural hizo posible el tránsito gradual de una economía agraria tradicional de subsistencia a otra de carácter industrial capitalista, tuvo lugar paralelamente al paulatino reemplazo de la idea de subordinación de los hombres a su medio natural por una nueva mentalidad, según la cual éstos pueden controlar la naturaleza y romper su tradicional relación de dependencia con respecto a ella. Se extendió, así, una conciencia antropocéntrica, que estaba en concordancia con las enormes posibilidades de actuación humana que ofrecían los avances científico-técnicos, y de la que participaba la generalidad de los clásicos del pensamiento sociológico, incluido el propio Marx. Éste, análogamente al resto de sus contemporáneos, también compartía la idea de que el hombre es el dueño absoluto del medio natural, el cual está completamente a su servicio dispuesto para ser conquistado y explotado de manera ilimitada ${ }^{1}$. Hablamos de conciencia antropocéntrica porque, de acuerdo con ella, de estar subordinada a los requerimientos de los ritmos y ciclos de la naturaleza, la humanidad pasaba a erigirse en un sujeto central del orden natural y cósmico, concebidos, sobre todo, como una realidad externa a ella, cuya voluntad y acción son decisivas en la explotación y transformación del mundo.

$\mathrm{El}$ antropocentrismo conllevaba el progresivo asentamiento de esa nueva forma de racionalidad que Weber (1979, p. 29) conceptuó como una racionalidad instrumental medios-fines, lo que suponía la paulatina instauración de una praxis (determinante/determinada de/por los adelantos tecnológicos que acompañaron su desarrollo) amparada en una mentalidad manipuladora de la realidad en general que, frente a las restricciones y carencias a las que se había encontrado sometida la humanidad hasta entonces, propugnaba la articulación racional de proyectos (a fin de cuentas, de medios instrumentales) encaminados a participar activamente en la regulación y modificación de la naturaleza, a romper los límites que imponía la misma para la trans-

${ }^{1}$ Aunque Marx contempló la importancia de lo que se denomina la "naturaleza" como fuente de riqueza y aunque llegó a percatarse de que el proceso productivo desarrollado por el sistema capitalista pone en peligro la "naturaleza", no llegó a superar el antropocentrismo característico de los pensadores de su tiempo. Es más, este antropocentrismo está tan arraigado en Marx que, para él, la "naturaleza" no produce por sí misma valor, sino que sólo transfiere su propio valor en el proceso de trabajo. Tal proceso, que para Marx es una de las actividades básicas del ser humano, constituye una de las bases fundamentales de ese antropocentrismo o de lo que es igual del protagonismo central que dicho autor otorga al hombre en la gestión del funcionamiento y del cambio de la "naturaleza" (Marx, 1975). 
formación del mundo y el desarrollo de las fuerzas productivas. Estaba extendida la presuposición, más o menos explícita o implícita, de que los recursos de la naturaleza eran prácticamente inagotables y de que ésta estaba ahí para ser explotada por los hombres sin ninguna restricción. Se consideraba que las posibilidades de crecimiento eran virtualmente infinitas. Todo esto estaba de acuerdo con una visión prometéica de la tarea de los actores humanos individuales y colectivos, según la cual éstos eran concebidos como artífices del funcionamiento y de la explotación de los recursos supuestamente ilimitados del planeta, como protagonistas activos del cambio y, en definitiva, "como productores del progreso", entendido "como algo que ha de alcanzarse, construirse, desarrollarse, y que requiere por tanto un esfuerzo creativo, una lucha, una búsqueda" (Sztompka, 1995, p. 54).

Esta mentalidad estaba en pleno vigor cuando, después de la Segunda Guerra Mundial, el medio rural de los países avanzados experimentó un proceso de progresiva modernización y mecanización de las tareas de labranza. La aplicación de los conocimientos científicos y técnicos entonces existentes a la agricultura se hacía orientada por la suposición y la confianza de que, por fin en su historia, los seres humanos tenían los medios para superar las ancestrales limitaciones y carencias de las tradicionales economías agrarias de subsistencia, por fin era posible aumentar e intensificar la producción hasta alcanzar unas cotas hasta entonces inimaginables; el crecimiento económico pasaba a erigirse en el principal indicador de desarrollo y de progreso. Desde la conciencia antropocéntrica que orientaba y alentaba esta visión cuantitativista y productivista (expansión de la producción frente a las carencias seculares de las economías agrarias de subsistencia del medio rural tradicional) del desarrollo, el medio agrario, como la generalidad del entorno natural, estaba ahí, como una realidad externa a los hombres, dispuesto para ser explotado sin ninguna limitación, lo único que se precisaba era poner en práctica los métodos y las técnicas de cultivo adecuadas para conseguir de él unos incrementos de la productividad y de la producción, así como unos beneficios cuya evolución se suponía tendería hacia un continuo incremento.

Bajo la orientación de estas premisas, se ponían en práctica unas nuevas formas de agricultura tecnificada que iban reemplazando a las tradicionales prácticas agrarias y que conllevaban serios peligros para la renovabilidad natural de los ecosistemas rurales, tal y como correspondía a una visión fragmentaria de los mismos, los cuales, a medida que avanzaban y se afianzaban estas nuevas formas de agricultura, tendían a dejar de ser concebidos como ámbitos en los que una población producía, vivía y consumía lo producido para pasar a ser considerados, sobre todo, como lugares destinados a la producción. En consonancia con ello, más que hacia la población rural en general, el interés de las políticas agrarias de entonces se dirigía hacia los agricultores, en tanto que productores, cuyo grado de preparación para desarrollar las tareas de cultivo y producción de alimentos se trataba de mejorar: la llamada profesionalización de este sector. En tal situación, de acuerdo con la racionalidad instrumental medios-fines que como hemos dicho antes constituye uno de los pilares básicos de legitimación y sustentación de la conciencia antropocéntrica, la eficacia en los métodos de producción y en el incremento de los rendimientos de ésta pasaban a erigirse en los objetivos centrales. Para conseguir estos objetivos, los impulsores del proceso de modernización de la agricultura concentraron sus esfuerzos fundamentalmente en favorecer la dimensión productiva del agro, lo que, como es sabido, acabó por dar lugar a una creciente degradación de la calidad de éste como medio de vida y, a la larga, también de la calidad de los productos agrarios producidos mediante el abuso de fertilizantes, de los pesticidas y de otros productos químicos usados en el cultivo.

En el caso específico de España, el proceso de modernización agraria comenzó a partir de los años cincuenta del siglo XX. Este proceso y el consiguiente afianzamiento del antropocentrismo productivista en la agricultura española tuvieron lugar en el marco del relativo aislamiento que, para nuestra situación 
sociopolítica, supuso el régimen dictatorial franquista. De la particular evolución del agro hispano a que esta situación dio lugar nos ocupamos a continuación.

\section{El agro español: de la ideología franquista de la "soberanía política del campesinado" al desarrollismo productivista}

El régimen de Franco se impuso en sus inicios como una opción que formalmente pretendía favorecer la cultura y el modo de vida agrarios tradicionales frente a la modernización. Sin embargo, esto no ha de ser entendido en el sentido de que el franquismo fuera favorable a los intereses de todo el campesinado, pues, de hecho, supuso un reforzamiento brutal de la posición hegemónica de las clases terratenientes más reaccionarias del Antiguo Régimen. El poder de estas clases había persistido prácticamente intacto en sus nuevas manifestaciones oligárquico-caciquiles durante la Restauración monárquica (1875-1917) y la dictadura de Primo de Rivera (1923-1930), y apenas había sido afectado durante el breve paréntesis republicano.

Los discursos programáticos e ideológicos iniciales del régimen franquista abogaban por un ideal de lo rural como ámbito de una armonía y de una integración social corporativa más allá de las divisiones entre las clases. En este sentido, la actuación de este régimen, análogamente a lo acaecido en la Alemania de Hitler, en la Italia de Mussolini o en el Portugal de Salazar, estaba legitimada por una doctrina política que propugnaba la organización de la sociedad en estructuras corporativas de naturaleza profesional. Este corporativismo, estatalmente controlado o regulado, era propuesto como alternativa para superar y evitar los conflictos, los desequilibrios y la desintegración social que, a juicio de tales regímenes, implicaba la acción sociopolítica de los partidos y sindicatos en tanto que instrumentos de la lucha de clases. Sin duda, las profundas crisis y la inestabilidad en que se encontraban los países referidos contribuyó a que en ellos se establecieran y afianzaran estos sistemas autoritarios.

En consonancia con la retórica integradora que legitimaba el corporativismo entonces preponderante, la política agraria franquista se basó, sobre todo en su primera etapa, en lo que Sevilla-Guzmán califica como la ideología de la soberanía política del campesinado. Ésta fue construida por agrónomos, juristas, clérigos y algunos economistas. que no tenían una específica formación sociológica y cuyas principales referencias eran el catolicismo social y los presupuestos doctrinales falangistas. La ideología de la soberanía política del campesinado se sustentaba en unos esquemas teóricos de la realidad que tenían como elemento clave la mitificación de la población rural y la idealización bucólica de la agricultura, concebida, más que como una actividad económica, como un modo de vida tradicional que era superior moralmente al urbano (Sevilla-Guzmán, 1979, p. 41). A través de esta ideología se manifestaba una aspiración a conservar o a crear un modelo armónico e integrado del mundo rural al margen de cualquier conflicto social, que estaba muy de acuerdo con los presupuestos corporativistas y negadores de los antagonismos sociales típicos del franquismo?

A pesar de sus originarios planteamientos tradicionalistas y agraristas, especialmente a partir de la década de los cincuenta del siglo XX, el régimen franquista fue dejando gradualmente de lado la ideología de la soberanía política del campesinado, a la vez que de facto se entraba en un proceso de modernización general de la sociedad española que se tradujo en una creciente industrialización de ésta, así como de mecanización y de modernización de su sector agrario. Durante un período de transición, los discursos legitimadores de la política agraria franquista oscilaron entre las posiciones ideológicas

\footnotetext{
${ }^{2} \mathrm{Al}$ adoptar esta visión integradora y armónica de la sociedad, la dictadura de Franco se comportaba de acuerdo con los esquemas y presupuestos de funcionamiento de lo social inherentes al fascismo. Sin embargo, conviene precisar que, a pesar de su carácter autoritario y de sus semejanzas con los regímenes fascistas, la naturaleza sociopolítica del franquismo fue globalmente diferente de la de aquellos. Sí fue claramente fascista Falange Española, encabezada por José Antonio Primo de Rivera.
} 
favorables a mantener la antigua situación y las partidarias de optar por los nuevos planteamientos modernizadores. No puede dejar de referirse aquí, la decisiva función que en dicho período desempeñó la "Ley de colonización e interés local", en lo que respecta a la creación de las condiciones que hicieron posible la modernización tecnológica mediante el apoyo financiero a las inversiones encaminadas a este fin (Castelló, 1970). Pero, sobre todo, para entender las razones y circunstancias que determinaron la nueva orientación ideológica que, a partir de aquellos años, se le comenzó a dar a la política agraria española, hay que tener en cuenta que, tras el período de autarquía que sucedió a la Guerra Civil, se produjo una creciente apertura hacia el exterior de la economía del país como consecuencia del desbloqueo internacional. Como es sabido, esto se vio facilitado, en gran medida, por el establecimiento de bases militares norteamericanas en España y porque, a raíz del advenimiento de la guerra fría, el régimen de Franco pasó, de ser considerado como próximo a los totalitarismos nazi o fascista, a ser visto como un potencial aliado de Occidente en su enfrentamiento contra el comunismo. Además, hay que tomar en cuenta, que, paralelamente a esto, tenía lugar el progresivo reemplazo en la elite dirigente franquista de los grupos y/o las ideologías falangistas tradicionalistas agraristas por una mentalidad favorable a la modernización técnica y económica que estaba representada, sobre todo, por los miembros del Opus Dei, los cuales, a partir de entonces, entraron a formar parte del gobierno como destacados artífices del proceso de industrialización y modernización en aquellos años iniciado. En este contexto fue acuñado el término desarrollismo para hacer referencia a la peculiar manera española de entender y buscar el desarrollo. Así, aunque el desarrollismo, análogamente a lo que acaecía en los procesos de desarrollo vigentes entonces en los países industriales avanzados, buscaba el crecimiento económico y la intensificación y el aumento de la producción (productivismo), en el caso español todo esto tenía lugar en una situación de falta de democracia, para cuya consecución tampoco se ponían en marcha los cambios sociopolíticos necesarios. Estos cambios era pospuestos con el pretexto de que el país no estaba todavía preparado para vivir en democracia y de que el mero desarrollo económico y técnico (de ahí, como hemos dicho, la expresión desarrollismo) tendrían como uno de sus efectos el propiciar las transformaciones que llevarían al establecimiento de las condiciones necesarias para el afianzamiento y la viabilidad de la democracia.

Aparte de estas razones contextuales, en la paulatina orientación de la agricultura española hacia el desarrollismo, en tanto que forma peculiar de adopción de lo que aquí hemos conceptuado como el antropocentrismo productivista, tuvo una importancia decisiva la creación, en 1955, del Servicio de Extensión Agraria (SEA). Este hecho determinó que, a partir de aquella fecha, la política agraria empezara a regirse, cada vez más, por criterios y objetivos más técnico-económicos que sociales, buscando una mayor profesionalización y eficacia económica. Con objeto de conseguir tales propósitos, paralelamente a la creación del SEA, se procedió a la reorganización de la enseñanza y de la investigación agrarias, creándose el Instituto Nacional Agronómico, dependiente de los ministerios de Agricultura y de Educación, con el cometido de emprender la modificación de los planes de estudios en la Escuela Especial de Ingenieros Agrónomos y en la de Peritos Agrícolas, así como con el fin de aproximar los técnicos a las características de las diversas agriculturas españolas y a las necesidades de los agricultores (Gómez Benito, 1995, p. 204; Sevilla-Guzmán, 1979, p. 182).

La aplicación de estas políticas agrarias hizo posible un proceso de industrialización general, así como de modernización y mecanización del sector agrario. Como consecuencia, se experimentó el trasvase de una gran proporción de fuerza de trabajo del campo a los sectores industrial y de servicios, lo que implicó un masivo éxodo de población rural a los centros urbanos que, junto con la notable cantidad de emigrados al extranjero, supuso un relativo alivio para la situación de los trabajadores que se quedaron en el campo, los cuales vieron elevados sus salarios, a la vez que se produjo una considerable mejora de sus condiciones de vida y posibilidades de encontrar 
sociopolítica, supuso el régimen dictatorial franquista. De la particular evolución del agro hispano a que esta situación dio lugar nos ocupamos a continuación.

\section{El agro español: de la ideología franquista de la "soberanía política del campesinado" al desarrollismo productivista}

El régimen de Franco se impuso en sus inicios como una opción que formalmente pretendía favorecer la cultura y el modo de vida agrarios tradicionales frente a la modernización. Sin embargo, esto no ha de ser entendido en el sentido de que el franquismo fuera favorable a los intereses de todo el campesinado, pues, de hecho, supuso un reforzamiento brutal de la posición hegemónica de las clases terratenientes más reaccionarias del Antiguo Régimen. El poder de estas clases había persistido prácticamente intacto en sus nuevas manifestaciones oligárquico-caciquiles durante la Restauración monárquica (1875-1917) y la dictadura de Primo de Rivera (1923-1930), y apenas había sido afectado durante el breve paréntesis republicano.

Los discursos programáticos e ideológicos iniciales del régimen franquista abogaban por un ideal de lo rural como ámbito de una armonía y de una integración social corporativa más allá de las divisiones entre las clases. En este sentido, la actuación de este régimen, análogamente a lo acaecido en la Alemania de Hitler, en la Italia de Mussolini o en el Portugal de Salazar, estaba legitimada por una doctrina política que propugnaba la organización de la sociedad en estructuras corporativas de naturaleza profesional. Este corporativismo, estatalmente controlado o regulado, era propuesto como alternativa para superar y evitar los conflictos, los desequilibrios y la desintegración social que, a juicio de tales regímenes, implicaba la acción sociopolítica de los partidos y sindicatos en tanto que instrumentos de la lucha de clases. Sin duda, las profundas crisis y la inestabilidad en que se encontraban los países referidos contribuyó a que en ellos se establecieran y afianzaran estos sistemas autoritarios.

En consonancia con la retórica integradora que legitimaba el corporativismo entonces preponderante, la política agraria franquista se basó, sobre todo en su primera etapa, en lo que Sevilla-Guzmán califica como la ideología de la soberanía política del campesinado. Ésta fue construida por agrónomos, juristas, clérigos y algunos economistas, que no tenían una específica formación sociológica y cuyas principales referencias eran el catolicismo social y los presupuestos doctrinales falangistas. La ideología de la soberanía política del campesinado se sustentaba en unos esquemas teóricos de la realidad que tenían como elemento clave la mitificación de la población rural y la idealización bucólica de la agricultura, concebida, más que como una actividad económica, como un modo de vida tradicional que era superior moralmente al urbano (Sevilla-Guzmán, 1979, p. 41). A través de esta ideología se manifestaba una aspiración a conservar o a crear un modelo armónico e integrado del mundo rural al margen de cualquier conflicto social, que estaba muy de acuerdo con los presupuestos corporativistas y negadores de los antagonismos sociales típicos del franquismo ${ }^{2}$.

A pesar de sus originarios planteamientos tradicionalistas y agraristas, especialmente a partir de la década de los cincuenta del siglo XX, el régimen franquista fue dejando gradualmente de lado la ideología de la soberanía política del campesinado, a la vez que de facto se entraba en un proceso de modernización general de la sociedad española que se tradujo en una creciente industrialización de ésta, así como de mecanización y de modernización de su sector agrario. Durante un período de transición, los discursos legitimadores de la política agraria franquista oscilaron entre las posiciones ideológicas

${ }^{2} \mathrm{Al}$ adoptar esta visión integradora y armónica de la sociedad, la dictadura de Franco se comportaba de acuerdo con los esquemas y presupuestos de funcionamiento de lo social inherentes al fascismo. Sin embargo, conviene precisar que, a pesar de su carácter autoritario y de sus semejanzas con los regímenes fascistas, la naturaleza sociopolítica del franquismo fue globalmente diferente de la de aquellos. Sí fue claramente fascista Falange Española, encabezada por José Antonio Primo de Rivera. 
favorables a mantener la antigua situación y las partidarias de optar por los nuevos planteamientos modernizadores. No puede dejar de referirse aquí, la decisiva función que en dicho período desempeñó la "Ley de colonización e interés local", en lo que respecta a la creación de las condiciones que hicieron posible la modernización tecnológica mediante el apoyo financiero a las inversiones encaminadas a este fin (Castelló, 1970). Pero, sobre todo, para entender las razones y circunstancias que determinaron la nueva orientación ideológica que, a partir de aquellos años, se le comenzó a dar a la política agraria española, hay que tener en cuenta que, tras el período de autarquía que sucedió a la Guerra Civil, se produjo una creciente apertura hacia el exterior de la economía del país como consecuencia del desbloqueo internacional. Como es sabido, esto se vio facilitado, en gran medida, por el establecimiento de bases militares norteamericanas en España y porque, a raíz del advenimiento de la guerra fría, el régimen de Franco pasó, de ser considerado como próximo a los totalitarismos nazi o fascista, a ser visto como un potencial aliado de Occidente en su enfrentamiento contra el comunismo. Además, hay que tomar en cuenta, que, paralelamente a esto, tenía lugar el progresivo reemplazo en la elite dirigente franquista de los grupos y/o las ideologías falangistas tradicionalistas agraristas por una mentalidad favorable a la modernización técnica y económica que estaba representada, sobre todo, por los miembros del Opus Dei, los cuales, a partir de entonces, entraron a formar parte del gobierno como destacados artífices del proceso de industrialización y modernización en aquellos años iniciado. En este contexto fue acuñado el término desarrollismo para hacer referencia a la peculiar manera española de entender y buscar el desarrollo. Así, aunque el desarrollismo, análogamente a lo que acaecía en los procesos de desarrollo vigentes entonces en los países industriales avanzados, buscaba el crecimiento económico y la intensificación y el aumento de la producción (productivismo), en el caso español todo esto tenía lugar en una situación de falta de democracia, para cuya consecución tampoco se ponían en marcha los cambios sociopolíticos necesarios. Estos cambios era pospuestos con el pretexto de que el país no estaba todavía preparado para vivir en democracia y de que el mero desarrollo económico y técnico (de ahí, como hemos dicho, la expresión desarrollismo) tendrían como uno de sus efectos el propiciar las transformaciones que llevarían al establecimiento de las condiciones necesarias para el afianzamiento y la viabilidad de la democracia.

Aparte de estas razones contextuales, en la paulatina orientación de la agricultura española hacia el desarrollismo, en tanto que forma peculiar de adopción de lo que aquí hemos conceptuado como el antropocentrismo productivista, tuvo una importancia decisiva la creación, en 1955, del Servicio de Extensión Agraria (SEA). Este hecho determinó que, a partir de aquella fecha, la política agraria empezara a regirse, cada vez más, por criterios y objetivos más técnico-económicos que sociales, buscando una mayor profesionalización y eficacia económica. Con objeto de conseguir tales propósitos, paralelamente a la creación del SEA, se procedió a la reorganización de la enseñanza y de la investigación agrarias, creándose el Instituto Nacional Agronómico, dependiente de los ministerios de Agricultura y de Educación, con el cometido de emprender la modificación de los planes de estudios en la Escuela Especial de Ingenieros Agrónomos y en la de Peritos Agrícolas, así como con el fin de aproximar los técnicos a las características de las diversas agriculturas españolas y a las necesidades de los agricultores (Gómez Benito, 1995, p. 204; Sevilla-Guzmán, 1979, p. 182).

La aplicación de estas políticas agrarias hizo posible un proceso de industrialización general, así como de modernización y mecanización del sector agrario. Como consecuencia, se experimentó el trasvase de una gran proporción de fuerza de trabajo del campo a los sectores industrial y de servicios, lo que implicó un masivo éxodo de población rural a los centros urbanos que, junto con la notable cantidad de emigrados al extranjero, supuso un relativo alivio para la situación de los trabajadores que se quedaron en el campo, los cuales vieron elevados sus salarios, a la vez que se produjo una considerable mejora de sus condiciones de vida y posibilidades de encontrar 
trabajo. Aunque, hay que precisar que en la generalidad del agro hispano siempre persistió una apreciable proporción de desempleo y se mantuvo intacta la situación social inherente a las profundas desigualdades estructurales existentes en el reparto de la propiedad de la tierra, problemática que nunca fue afrontada realmente por el franquismo.

Análogamente a lo sucedido en otros procesos de modernización de las sociedades avanzadas industriales de nuestro entorno, lo urbano constituía por aquellos años el paradigma de progreso, de desarrollo y de civilización, frente a lo rural que era considerado como la manifestación de un mundo paleto y atrasado que debía de ser superado. A la vez que se devaluaba como forma de cultura y de vida, la ruralidad pasaba a ser concebida, sobre todo, como un mero espacio especializado en la producción agraria, la cual cada vez se fue ajustando más a las exigencias productivistas, de competitividad y de profesionalización características de otros procesos de modernización e industrialización.

En 1975, tras la muerte del general Franco que dio paso a la consiguiente instauración de la democracia, los objetivos de la política agraria, tanto en lo que se refiere a la Unión de Centro Democrático (UCD) como al posterior gobierno del Partido Socialista Obrero Español (PSOE), continuaron participando, en gran medida, del antropocentrismo productivista antes referido, el cual, con más o menos acusadas diferencias, seguía entonces estando en vigor en el ámbito de la Europa comunitaria. No obstante, cuando el día $1^{\circ}$ de enero de 1986 tuvo lugar la incorporación de España a la entonces denominada Comunidad Económica Europea (CEE), la política agraria comunitaria (PAC) se encontraba ya en fase de revisión de sus tradicionales presupuestos favorables a la protección y el fomento del productivismo. El proceso de adaptación de la agricultura española a las exigencias de la PAC conllevó la necesidad de una fuerte reestructuración en diversas zonas y diferentes sectores de nuestro medio agrario.
Éste ha estado tradicionalmente especializado en una serie de productos denominados continentales (carne, leche, cereales, remolacha o patatas) en los que Europa es excedentaria y, además, debido a sus más altos niveles de competitividad, los produce a costes más baratos. Con el fin de adecuarse a la realidad de la agricultura europea, la política agraria de nuestro país ha venido incentivando la reducción, cuando no el desmantelamiento, de la infraestructura destinada a tales productos, bastante extendidos en Galicia, Extremadura, Asturias y Castilla-León, que han experimentado el impacto de medidas restrictivas de la PAC como las cuotas de producción o las congelaciones de precios. Un caso especialmente preocupante es el de las zonas de cultivo de cereales, sobre todo a raíz de las restricciones de la reforma de la PAC de mayo de 1992, que implicaron una considerable disminución de la proporción de tierras destinadas a este cultivo. Al desaparecer gradualmente la base productivo-económica que sustentaba el entramado social del medio rural, zonas enteras de la España interior y de la cornisa cantábrica han experimentado una intensificación de sus procesos de despoblamiento y de creciente deterioro.

Dos objetivos importantes de la reforma de la PAC a la que venimos haciendo referencia $\operatorname{eran}^{3}$, de una parte, encarar el problema de la superproducción que daba lugar a una enorme acumulación de excedentes productivos de muy difícil comercialización, $y$, de otra, poner freno a la sobreexplotación productivista de la tierra, que amenazaba la preservación del equilibrio medioambiental de los ecosistemas agrarios. A fin de conseguir estos objetivos, se pusieron en marcha una serie de disposiciones de la PAC, tendentes a propiciar el desarrollo sostenible del medio rural y, sobre todo, a evitar la superproducción y los enormes costes económicos que suponía la financiación del modelo productivista en el que la misma se sustentaba. Esto condujo a apoyar la extensificación y el control de la producción vía cuotas, frente al anterior énfasis en el aumento de

\footnotetext{
${ }^{3}$ En el apartado de este trabajo titulado "La creciente regulación medioambiental de la agricultura por la Unión Europea" expondremos con más detalle el contenido de esta reforma.
} 
los rendimientos y de la competitividad. Como consecuencia, los agricultores se encuentran más incentivados para el "mantenimiento del status quo" que para seguir el tradicional camino de la intensificación productiva (Etxezarreta y Viladomiú, 1997, p. 321).

En general, las referidas restricciones a la producción o las reestructuraciones de ésta a escala europea están generando incertidumbre y preocupación entre bastantes agricultores comunitarios, precisamente en una situación de creciente inserción de la agricultura en la lógica socioeconómica globalizada que opera a escala planetaria. Una pregunta clave, que han de formularse todos los encargados de poner en práctica o llevar a cabo la elaboración de las políticas agrarias derivadas de las presentes directrices de la PAC, es: ¿como podrán materializarse estrategias de desarrollo sostenible viables para todas esas zonas del agro español, cuya crisis se ha acentuado precisamente como consecuencia de la aplicación de las actuales directrices de las políticas agrarias de la Unión Europea (UE)?

Excedería los límites y los cometidos de este trabajo tratar de encontrar posibles respuestas a esta pregunta, pues lo que nos interesa ahora es tratar de explicar las razones del paulatino declive de las maneras de concebir el agro y sus usos orientadas y legitimadas por lo que aquí denominamos antropocentrismo productivista. Como veremos a continuación, a la generación de ese declive han contribuido el aumento de las disposiciones de la UE encaminadas a la regulación medioambiental de la agricultura y, sobre todo, el hecho de que se estén experimentando unas tendencias, cada vez más acentuadas, hacia la revalorización de la ruralidad como habitat y paradigma de calidad de vida, en un contexto de creciente afianzamiento de lo que aquí tipificamos como un ecocentrismo naturalista.

\section{La creciente regulación medioambiental de la agricultura por la Unión Europea}

La regulación medioambiental de las actividades industriales se produjo como resultado de un aumento de la preocupación en las sociedades occidentales, durante la década de los setenta del siglo $\mathrm{XX}$, por los daños ecológicos causados como consecuencia del fuerte desarrollo económico que venían experimentando dichas sociedades desde unas décadas atrás. Dentro de esta regulación medioambiental, la agricultura se mantuvo libre de los controles impuestos a los sectores industriales. Este status de excepcionalidad medioambiental de la agricultura se justificaba a través de diversas razones (Whitby, 1996): el carácter difuso de la contaminación agrícola al producirse en explotaciones familiares dispersas y atomizadas; la naturaleza diversa y, en ocasiones, retardada de la contaminación agrícola; la consideración de la agricultura como una actividad armónica con la naturaleza; las políticas proteccionistas que favorecían el aumento e intensificación de la producción agraria (productivismo) frente a criterios medioambientalistas.

Sin embargo, en la década de los ochenta, el debate agroambiental comenzó a tener un importante desarrollo, especialmente en el ámbito de la Europa comunitaria. Como consecuencia de la mayor regulación medioambiental del sector industrial, la contaminación producida por el sector agrario, que durante dicha década continuó experimentando una gran intensificación en sus formas de producción amparándose en criterios productivistas, se hizo más visible. En este contexto, empezaron a plantearse en el ámbito comunitario las implicaciones ambientales del modelo intensivo de producción agraria. Bajo la influencia de algunos Estados miembros (Gran Bretaña, defendiendo la relación estrecha entre agricultura y paisaje; Dinamarca y Holanda, con graves problemas medioambientales ocasionados por la agricultura intensiva), la UE fue introduciendo un nuevo discurso sobre las relaciones entre agricultura y medio ambiente que terminó materializándose en las primeras normas de corte ambiental en la agricultura (Garrido, 1998). La agricultura comenzaba así a ser tratada como una actividad contaminante más, perdiendo su anterior status de excepcionalidad.

En 1992, la UE introdujo una serie de cambios importantes en la PAC; además de sustituir los me- 
canismos de apoyo a los precios por pagos directos a los agricultores por superficie y desligados de la producción, se aprobaron tres medidas entre las que se incluía la ayuda a métodos de producción agraria que fuesen compatibles con el respeto y la conservación del medio ambiente. Estas medidas, conocidas como el programa agroambiental, constituían una novedad ya que, por primera vez, se aprobaba en la UE un conjunto estructurado de normas de cumplimiento obligatorio para los países miembros, cuya finalidad era propiciar la introducción de prácticas de agricultura sostenible (Garrido, 1999, p. 28).

\section{Del declive del antropocentrismo produc- tivista hacia un ecocentrismo naturalista}

La creencia, $\tan$ extendida en el período de vigencia del antropocentrismo productivista, de que era posible mantener un crecimiento prácticamente ilimitado se sustentaba en lo que Nisbet ha calificado como la "engañosa metáfora del crecimiento", según la cual se presuponía que había una analogía entre el cambio de la sociedad y los procesos de crecimiento de un organismo individual (Nisbet, 1969, p. 166). Si bien esta idea propició los grandes avances que dieron lugar al relativamente elevado nivel socioeconómico actual, el hecho es que hoy nos hemos percatado de la necesidad de poner límites al crecimiento económico si no queremos destruir nuestro propio entorno ecológico. Ello, sobre todo, porque como consecuencia de los excesos cometidos en nombre del antropocentrismo productivista aparecen el efecto invernadero, la lluvia ácida, los agujeros en la capa de ozono, la deforestación, la desertización, la contaminación del agua, la extinción de especies animales y vegetales... una larga secuencia que sólo se verá detenida de producirse una nueva concepción de la relación hombre-naturaleza. Surge así la dramática y urgente necesidad de, sin cerrarse a las ventajas que ofrece para la producción agraria la implantación y extensión de las nuevas tecnologías, combinar esto con la consideración (muy extendida, como vimos, en las sociedades tradicionales) del medio rural como un ámbito de vida. El objetivo ha de ser favorecer "una nueva forma de producir que no sólo deje de suponer una amenaza para la vida de las generaciones futuras, sino que además introduzca en la actualidad una justicia social" (Sevilla Guzmán y López Calvo, 1993, p. 6).

En este sentido, hay que reconocer que cada vez está más generalizada la conciencia, tanto entre la población como entre las instituciones y organizaciones implicadas en las políticas agrarias y medioambientales, acerca de la necesidad de replantear la relación entre agricultura y naturaleza, lo que, sin duda, es una manera de contribuir a tratar de encontrar soluciones para el progresivo deterioro medioambiental que viene sufriendo el planeta. La extensión de dicha conciencia se enmarca en el contexto de unas crecientes preocupaciones por la búsqueda de lo que se ha dado en llamar desarrollo sostenible. No tomamos aquí en consideración la multiplicidad de significaciones y de prácticas a que hace referencia el concepto de desarrollo sostenible, el cual, como bien afirma Bill Adams (1993, p. 218), es una bandera de conveniencia bajo la que navegan todo tipo de iniciativas intelectuales y prácticas. Sólo queremos destacar el cambio ideológico que, al amparo de las ideas y actitudes suscitadas por la cada vez mayor extensión de dicho concepto, se produce en la década de los noventa, desde la consideración de la protección del medio ambiente como un freno al desarrollo económico (criterio productivista) a la valoración de la protección ambiental como motor del progreso económico (criterio basado en el desarrollo sostenible).

Este cambio se manifiesta en la conciencia colectiva, cada vez más extendida, acerca de la necesidad de buscar un nuevo marco paradigmático para la gestión y organización económica que ha de conducir a la implantación de un sistema de producción y consumo alternativo al todavía vigente de carácter productivista, con respecto al cual está comprobado que ya no puede seguir manteniéndose la idea de su ilimitada capacidad para aceptar modificaciones sin modificarse (Pérez Adán, 1994). Sin duda, contribuyen a favorecer el establecimiento de este nuevo marco paradigmático las cada vez mayores 
preocupaciones por preservar el medio ambiente para las generaciones futuras, así como el hecho de que tales preocupaciones traigan aparejada una concepción alternativa del desarrollo. De acuerdo con ésta, a diferencia de la noción de crecimiento que sugería la idea de cantidad e implicaba una visión de las relaciones con las cosas y las personas consideradas como objetos, ahora se trata de poner mayor énfasis en el término desarrollo que, entre otros aspectos, remite a la idea de transformación cualitativa y a la consideración de la relación con y entre las personas como sujetos. En este contexto, aún cuesta admitir que un verdadero desarrollo sostenible puede incluso llegar a representar un decrecimiento económico. Utilizando una expresión de Wallerstein (1991), no sólo se han de repensar los planteamientos sobre los que descansa la ciencia social, sino que se han de "despensar" muchos de esos planteamientos.

Pero, ¿cómo se ha llegado a una situación en la que los daños ocasionados, tanto al hombre como a la naturaleza, ponen en peligro una coevolución del primero y de la segunda de millones de años? Se trata del lado oscuro de la modernidad, una consecuencia no intencionada o prevista del ingente proceso de transformaciones socioeconómicas y de desarrollo tecnológico que ha conllevado la evolución histórica de la misma. El desarrollo tecnológico, que a lo largo del siglo XX ha alcanzado una intensidad y un grado de aceleración sin precedentes en la historia anterior de la humanidad, ha supuesto la adopción de innovaciones sin tener un conocimiento preciso y completo de su impacto medioambiental. Por lo tanto, la producción de riesgos ha pasado a convertirse en un hecho consustancial del avance tecnológico. No obstante, estos riesgos han sido asumidos por la sociedad enmascarándolos dentro de unos estándares sociales de aceptabilidad que ni son objetivos ni son temporal ni espacialmente estáticos. Así, por ejemplo, en los años cuarenta del siglo XX el DDT era considerado inofensivo para la salud humana; tres décadas más tarde, con un mejor conocimiento de sus riesgos (alta toxicidad y prolongada persistencia en el medio ambiente) fue prohibido en los países desarrollados.
Ha sido quizá Ulrich Beck (1992a, 1992b) quien ha llevado a cabo la más influyente caracterización sociológica de los riesgos tecnológicos asociados a las sociedades modernas. A diferencia de los análisis de la producción y distribución social de la riqueza en los que se ocupó la sociología al estudiar la sociedad industrial avanzada, Beck se centró en la producción social de riesgos que entraña la modernidad. Dos años antes, Anthony Giddens (1990) ya había abierto una senda en esta dirección cuando calificó a la modernidad como un fenómeno de doble filo, subrayando, por un lado, las grandes oportunidades de transformación social y de desarrollo que genera y, por otro, poniendo al descubierto su cara más oscura. Así, en la modernidad, como consecuencia de la ruptura con la tradición, se ha producido la institucionalización de la duda y hemos llegado a una situación de enormes peligros y riesgos. Todo esto nos ha obligado a algo más que a suavizar o matizar la suposición que alentaba la, tan extendida en el siglo XIX y parte del XX, idea de "progreso", según la cual el surgimiento de la modernidad nos conduciría a un mundo más feliz y seguro.

La modernidad avanzada, de acuerdo con Beck, presenta una clara diferencia respecto a cualquier momento histórico anterior: la distinta índole de sus riesgos. Mientras que en las sociedades preindustriales los riesgos eran naturales y externos, en la modernidad avanzada éstos pasan a tener un carácter industrial y a depender de ciertas decisiones políticas; siendo su alcance y poder de devastación globales, y abriendo un horizonte de daños irreparables (Beck, 1992b, p. 98). La globalización y omnipresencia del peligro transciende las diferencias sociales y económicas, suponiendo un riesgo no sólo para uno de los dos elementos de la relación hombrenaturaleza, como había ocurrido anteriormente, sino para la totalidad del planeta. Esto plantea un horizonte de incertidumbre e impotencia en el que no se trata ya de que no sepamos como acertar, sino de que ni siquiera podemos prever con exactitud en que medida nos equivocaremos.

En esta situación, en contraste con los objetivos productivistas de la era en que se buscaba sobre 
todo el crecimiento económico, actualmente, en el marco global de la superproducción, la estandarización productiva y las rutinas laborales, así como del alto nivel de burocratización imperantes en las sociedades industriales modernas avanzadas, se experimenta una tendencia hacia la implantación gradual de un nuevo modelo productivo más flexible que, en vez de centrarse en el mero incremento de productos homogéneos y despersonalizados, se encamina hacia la adopción de un sistema que genere productos especializados de calidad y diseño. Se trata de lo que puede conceptuarse como el paulatino tránsito del fordismo al posfordismo (Clarke, 1990, p. 73). En el sector agrario, dicho tránsito se manifiesta en que, mientras que antes el desarrollo consistía sobre todo en el crecimiento económico, en aumentar e intensificar la producción (antropocentrismo productivista), actualmente se tiende a enfatizar el fomento de la competitividad productiva a través de la mejora de la calidad y de la presentación ante el consumidor de los productos agrarios ${ }^{4}$. Pero, no se trata sólo de mejorar la calidad de estos productos, sino también la de las condiciones ambientales y vitales del entorno rural. Esto significa la necesidad de apostar por el establecimiento de formas sostenibles de desarrollo respetuosas con el medio ambiente y basadas en una explotación racional de los recursos que tengan en cuenta el carácter limitado de éstos y no conduzcan a su agotamiento. La búsqueda de la mejora de la calidad vital y ambiental, entendida de esta manera, se está traduciendo en una especie de reconstrucción social y vuelta a lo rural que, mientras que durante las anteriores fases de la modernización fue visto como un reducto del pasado, como un paradigma del atraso y del subdesarrollo, en la presente situación torna a ser considerado positivamente como un entorno cuyos modos de vida, formas de organización del trabajo y maneras "ecológicas" de cultivar tienden a revalorizarse (Entrena, 1998). Esta revalorización de lo rural, que se produce paralelamente al declive del etnocentrismo urbanoindustrial que legitimó, primero, la idea de "progreso" y, luego, las teorías de la modernización (así como las críticas a éstas), tiene lugar en un contexto, en el que cada vez es mayor el número de los que, como Jaime Loring, consideran que "el proyecto político, económico y social que en estos momentos debemos concebir ha de ser el proponerse que la agricultura y la aldea, no sean en adelante el símbolo de lo atrasado, de lo paleto, frente a la industria y la ciudad, símbolos de lo moderno y lo civilizado" (1992, p. 267). La ruralidad, de este modo, tiende a adquirir una consideración positiva, a la vez que es vista en su dimensión de habitat y como paradigma de forma y de calidad de vida deseables, frente a las tendencias preponderantes durante la vigencia del antropocentrismo productivista a considerarla básicamente como un lugar especializado en la producción de tipo agrícola.

En líneas generales, puede considerarse que es a partir de mediados de la década de los años ochenta cuando la agricultura ha comenzado a moverse hacia una era posproductivista (Ilbery, 1992), habiendo evolucionado desde unos valores materialistas a otros posmaterialistas (Inglehart, 1991). Esos años son el punto de inflexión que marca el inicio de la transición desde un antropocentrismo productivista hacia un ecocentrismo naturalista; es decir, desde la concepción del ser humano como centro del universo hacia una creciente conciencia acerca de la necesidad de considerar al mismo como inmerso en un ecosistema físico-natural cuyo equilibrio medioambiental ha de procurar preservar. Con referencia a la ruralidad, esto supone la introducción de un nuevo discurso, en el que, más que la eficiencia y el mero incremento de la producción, se tiende a ver el medio agrario como un espacio natural, cuyo entorno medioambiental hay que conservar y proteger, a la vez que se trata de encaminar dicho medio hacia unos nuevos usos o funciones de carácter cinegético, turístico o artesanal.

\footnotetext{
${ }^{4}$ El término calidad es impreciso y está sujeto a diversas interpretaciones. Por ejemplo, para unos, los productos de mayor calidad son los de la agricultura "ecológica", los que el hecho de consumirlos proporciona una sensación de "vuelta a la naturaleza", precisamente en un mundo que está más alejado de ella que nunca; para otros, son los que son elaborados artesanalmente o son cultivados de acuerdo con directrices y procesos de control no sujetos a procedimientos agro-industriales....
} 
A manera de conclusión: posiciones y actitudes de la sociedad española ante la nueva ruralidad

Partiendo de la idea de que la ruralidad es el resultado de una construcción social, hemos analizado los cambios que se han experimentado en su concepción y en sus usos al pasar de la preponderancia del antropocentrismo productivista a la del ecocentrismo naturalista. Tales cambios constituyen el contexto en el que hay que ubicar las transformaciones producidas en la década de los noventa, tanto en las demandas sociales como en las políticas agrarias, que han dado lugar a un mayor énfasis en la ruralidad como entorno ecológico y a unas crecientes preocupaciones por preservar su equilibrio medioambiental para las generaciones futuras. La consideración de los valores paisajísticos, estéticos y socioculturales de ese entorno hace posible una diversificación de las actividades a realizar en él, más allá de su anterior función de producción y abastecimiento de alimentos.

Estas transformaciones en los usos y en la concepción de la ruralidad conllevan la exigencia de cambiar la relación entre la agricultura y su entorno natural, lo que, como señala Paniagua, plantea la demanda de un nuevo pacto social con los agricultores, el cual "no podría entenderse como una profunda problematización ambiental del medio rural y de la agricultura, sino como la generalización del aprovechamiento de entornos de calidad ambiental como práctica habitual dentro del tiempo de ocio, con cuya conservación los agricultores conseguirían una nueva legitimación social" (Paniagua, 1997, p. 990). La nueva relación entre la agricultura y el medio ambiente presenta unas características particulares según el ámbito regional o subregional en el que se desarrolla (Bodiguel y Buller, 1991). Estas características, que varían también de acuerdo con las peculiaridades de cada sistema agrícola, sólo pueden ser cabalmente entendidas si se considera dicho sistema como una construcción social específica resultante de la interrelación existente entre un contexto físico, unas determinadas condiciones económicas y un marco concreto de relaciones sociales entre la población.

La actual relación entre agricultura y medio ambiente suscita cambios en las posiciones y en las actitudes sociales ante lo rural. En este sentido, en el caso español, análogamente a lo que sucede en otros países desarrollados de nuestro entorno sociopolítico, observamos como, de una parte, persisten las posiciones y actitudes tendentes a defender los planteamientos antropocéntrico productivistas y, de otra, se extienden, cada vez más, las posiciones y las actitudes que, basándose en una concepción ecocéntrica de las relaciones de los hombres con la ruralidad, abogan por fórmulas de desarrollo sostenible respetuosas con el mantenimiento del equilibrio medioambiental. De todas formas, en nuestro país se observa todavía un alto grado de incumplimiento (en relación con lo que sucede en el resto de Europa) de la normativa comunitaria en materia medioambiental. Esto puede ser explicado en función de razones como las siguientes: la particular estructura autonómica del Estado que plantea ciertas dificultades a la hora de aplicar normas de carácter general en todo su territorio, el hecho de que entre las sociedades menos desarrolladas de la UE se encuentre España o, también, la celeridad con que en ésta fue incorporado el Derecho medioambiental europeo, cuando la capacidad de la estructura administrativa existente era inadecuada. Todo esto hace que haya podido afirmarse que "el apresuramiento de las autoridades españolas en promulgar las directivas medioambientales comunitarias obedecería a la necesidad de ser vistos como participando plenamente en Europa, más que a la existencia de una fuerte concienciación ambiental" (Izcara Palacios, 1999, p. 116).

Además, la manifestación de esta concienciación va asociada a posiciones y actitudes muy diferentes, según la situación particular de cada uno de los grupos o sectores sociales afectados por la nueva relación entre la agricultura y el medio ambiente o responsables de crear las condiciones que la hacen posible. Entre estos grupos o sectores, cabe mencionar las instituciones y organismos encargados 
de elaborar y/o poner en práctica las nuevas políticas agrarias, los empresarios agrícolas, las organizaciones agrarias, los movimientos o asociaciones ecologistas, etc. Dada la gran diversidad de situaciones de estos grupos o sectores sociales, sus posiciones y actitudes, que pueden ser concebidas como expresiones de la manera en que los mismos construyen y/o entienden las nuevas relaciones entre agricultura y medio ambiente y los cambios en los usos y en la concepción de la ruralidad que ello conlleva, son también muy diferentes y variadas.

De entre la diversidad de posiciones y de actitudes en relación con la nueva concepción de la ruralidad que pueden observarse en España, distinguimos a continuación tres tipos que pueden considerase básicos en este sentido; a saber: la posición institucional, la de los profesionales (los agricultores y sus organizaciones representativas) y las que aquí denominamos como posiciones ecologistas.

Tipo I) La posición institucional. La entrada en la UE ha supuesto la necesidad de adecuar la agricultura española a la normativa comunitaria y a los cambios que ésta estaba experimentado, al pasar del proteccionismo productivista hacia un mayor énfasis en la preservación del medioambiente. Además de esto, nuestra agricultura ha experimentado, simultáneamente, otro proceso de adaptación con el desarrollo en el interior del país del Estado de las Autonomías, lo cual ha venido a significar la transferencia completa en materia de agricultura desde la Administración Central a las Comunidades Autónomas. Estos dos procesos adaptativos (interior y hacia el contexto exterior europeo de nuestro entorno sociopolítico) han transformado de una manera radical el contexto general e institucional que regulaba la actividad del sector agrario en España, así como el marco en el que tienen lugar las relaciones sociales entre los distintos agentes sociales que intervienen en este sector.

Dada la heterogeneidad de situaciones, grupos e intereses a los que va dirigida la política rural de la UE, su posición institucional se caracteriza por su ambiguiedad y pretensión de integrar objetivos diferentes, cuando no contradictorios entre sí. Todo esto hace que pueda afirmarse que dicha política, en cuya aplicación en España desempeñan una labor decisiva el Ministerio de Agricultura, Pesca y Alimentación y las distintas Comunidades Autónomas, se presenta como la yuxtaposición de una política de mercados agrarios, una política estructural y una política medioambiental, con la intervención de instrumentos bastante complejos y sin homogeneidad global (UE, 1988). Al hallarse inmersa en el conjunto de las otras políticas rurales comunitarias, la política agroambiental europea aprobada por la UE en 1992 no responde a una lógica autónoma de protección del medio ambiente rural, encontrándose su filosofía imbuida por el carácter general de una reforma de la PAC, cuyo principal objetivo era el control del gasto agrícola mediante la eliminación de los incentivos productivistas a los agricultores para, de esta forma, reducir los excedentes. Por tanto, la posición institucional de la UE respecto a la nueva relación entre el hombre y la naturaleza se puede calificar como un intento de conservar el medio ambiente y de proteger el entorno natural a través de prácticas agrarias que sean compatibles con tal objetivo de la PAC. En otras palabras, la política agroambiental europea debe considerarse no como una política autónoma, sino como un subproducto de la reforma de la PAC.

Pese al corto período de tiempo transcurrido desde la aprobación de la política agroambiental, pueden mencionarse algunos factores significativos que influyen en su aplicación, tales como: a) la diferente sensibilidad de los gobiernos nacionales y de las propias organizaciones agrarias en la aplicación de tal política; b) la política agroambiental responde a la realidad de los países del norte y del centro de la UE, mientras que los países mediterráneos, entre los que se encuentra España, muestran mayores dificultades para aplicarla, ya que tienen una agricultura de carácter extensivo en la que los problemas ambientales son de una naturaleza distinta a los de los ecosistemas centroeuropeos; c) el importante déficit de competitividad que sufren las agriculturas mediterráneas en relación al centro y norte europeos (Garrido, 1998).

Tipo II) La posición de los profesionales. $\mathrm{La}$ transformación del marco institucional que regula la actividad agraria ha tenido un gran efecto sobre la 
visión que tienen los agricultores de su realidad socioeconómica, política y profesional más inmediata, así como sobre sus perspectivas de futuro. Esta nueva visión puede abordarse desde dos puntos de vista distintos pero complementarios: en primer lugar, desde el análisis de la opinión de los agricultores acerca del medio ambiente en general, y en segundo lugar, desde el análisis de la posición colectiva de las organizaciones agrarias que los representan.

Según encuestas realizadas en España (IDES ${ }^{5}$, 1986; CIRES, 1994), existe un bajo grado de extensión de la sensibilidad ambiental entre los agricultores españoles. Éstos opinan (en un 79\%), que la solución a los problemas ambientales debe pasar por cambios sociales, y no a través del desarrollo tecnológico (opción que sólo defienden el $21 \%$ restante). Preguntados por su actitud ante el hecho de pagar precios más altos por la protección del medio ambiente, los agricultores con tierras en propiedad fueron quienes mostraron una menor predisposición al respecto (un 33,3\% se mostraron muy contrarios o contrarios). Además, estos mismos agricultores propietarios fueron los que con mayor intensidad manifestaron que la política de defensa del medio ambiente era simplemente una moda o que era importante pero existían otros problemas de mayor relieve. En definitiva, la circunstancia de tener una propiedad parece suponer un freno a la sensibilidad medioambiental en el sector agrícola español.

En cuanto a la posición de las organizaciones agrarias representativas de los que ejercen la profesión de agricultores, se observan notables diferencias entre aquellas que están más próximas ideológicamente a la izquierda (por ejemplo, la Unión de Pequeños Agricultores - UPA) y las que represen$\tan$ los intereses de los que abogan por una agricultura más competitiva y rentable económicamente (es el caso de la Asociación Nacional de Jóvenes Agricultores - ASAJA). Así, mientras que las primeras suelen enfatizar la cuestión ambiental, las segundas insisten más en la dimensión empresarial de la actividad agraria. No obstante estas diferencias, las posiciones de ambos tipos de organizaciones coinciden en que si, se introduce el factor ambiental en la agricultura, la eficacia de ésta como actividad empresarial deja de ser la misma, por lo cual sería necesario que fuese mantenida gracias a la transferencia de fondos provenientes de las instituciones públicas. Esto supondría ligar la función ambiental del agricultor a la percepción de nuevas rentas que paliasen la disminución de ingresos que provoca la limitación medioambiental de la actividad productiva, produciéndose una sustitución paulatina de las "primas de productividad" por las "primas de conservación". Se plantearía así un nuevo papel del agricultor, uniéndose a su tradicional función productiva dos más: el desarrollo del mundo rural a través del uso de valores ambientales, y la protección del medio ambiente (Paniagua, 1997, p. 992).

Tipo III) Las posiciones ecologistas. Incluimos aquí las posiciones y actitudes que, sin ser encuadrables en ninguno de los grupos sociales referidos en los tipos I y II, se muestran, explícita o implícitamente, favorables a la concepción y el uso del mundo rural y/o de la agricultura de acuerdo con los nuevos planteamientos ecocéntricos actualmente en vigor. A este respecto, en primer lugar, cabe mencionar a los grupos y movimientos ecologistas. En unas circunstancias, en las que se ha ido extendiendo la conciencia ecológica de la población, expresada a través de un aumento de la presión a las instituciones en favor de la introducción de una serie de medidas correctoras con el objetivo de restringir el uso de plaguicidas y fertilizantes y la eliminación de vertidos agrícolas (el llamado proceso de ambientalización de la agricultura), tales grupos y movimientos aprovecharon la coyuntura favorable para, gracias al creciente apoyo popular recibido, aumentar su influencia política, presionando no sólo en la dirección de imponer controles a la contaminación generada por la agricultura, sino también en favor de una agricultura menos intensiva y, por lo tanto, más

${ }^{5}$ Encuesta realizada a comienzos de 1986 para la Dirección General de Medio Ambiente por el Instituto IDES. Se hicieron 2017 entrevistas a escala nacional, tomando como universo la población española de ambos sexos de 18 o más años. 
respetuosa con el medio ambiente. La posición de los ecologistas con respecto a la nueva relación entre el hombre y la naturaleza presenta así un carácter dual: por un lado, una dimensión agraria, imbricada directamente con los problemas ambientales de los sistemas intensivos de producción; y por otro, una dimensión rural, estrechamente conectada con los efectos sobre el medio ambiente del uso cada vez más creciente de los espacios rurales como lugares de ocio y diversión por parte de una ciudadanía que dispone de un mayor tiempo libre (Moyano y Paniagua, 1998). De ahí, que los debates actuales en el seno del ecologismo sobre la relación entre hombre y naturaleza vayan en la dirección de implantar una serie de límites al acceso masivo a la naturaleza de la población, así como de controlar los efectos ambientales de dicho acceso, bien a través de mecanismos propios del mercado, o bien a través de regulaciones elaboradas con este propósito.

Por otra parte, en las posiciones y en las actitudes de los ecologistas se manifiesta una nueva relación de la sociedad humana con la naturaleza, en la que, si bien se toma en cuenta la dialéctica de interdependencia e interinfluencia entre ambas y'se consiguen evitar los excesos del antropocentrismo productivista, emergen, a veces, unas ideas de la nueva ruralidad, en las que se manifiestan visiones fundamentalistas y religioso místicas de lo ecológico, que es concebido desde una especie de "piedad cósmica que acaba negar o cuestionar los indudables logros alcanzados con la modernización y la industrialización, a la vez que por reducir la perspectiva ecológica a un mero discurso conservacionista (Giner y Tábara, 1998). Este discurso está desprovisto, casi por completo, de la necesaria conciencia democrática en la que debe basarse dicha perspectiva; entendida esta conciencia en el sentido de participación y/o control colectivo, por parte de la población, en los procesos socioeconómicos que afectan a la gestión de su entorno vital, en este caso, desde el punto de vista medioambiental.

Por último, queremos mencionar como el, cada vez mayor, arraigo entre la población española de las posiciones y las actitudes ecologistas da lugar a que en nuestro país, de manera similar a lo que acontece en otras sociedades avanzadas, tenga lugar el desarrollo de ciertas propensiones sociales tendentes a instrumentalizar lo ecológico (y por ende la nueva ruralidad a ello asociada) como artículo de venta y de consumo. Ejemplos de esto son las inmobiliarias o las agencias de turismo que venden paisaje y naturaleza mediante sus propuestas residenciales o de turismo rural, o, también, las cada vez más frecuentes ofertas que podemos encontrar de determinados "productos naturales"; es decir, cultivados de acuerdo con una "agricultura ecológica". En España, como en los países de nuestro entorno, el mercado de este tipo de agricultura se encuentra en expansión, en gran medida, debido a las crecientes preocupaciones de la población por los posibles efectos negativos para la salud que puedan derivarse del consumo de alimentos genéticamente transformados o de frutas y verduras tratadas con diversos fertilizantes químicos o productos fitosanitarios, que son altamente tóxicos y contaminantes. Otros hechos que contribuyen especialmente a incrementar la demanda de estos "productos ecológicos" son los repetidos escándalos alimentarios asociados a ese productivismo industrial que tiene lugar al margen del control de los consumidores, tales como el escándalo de las "vacas locas" en 1996 en Gran Bretaña o, más recientemente en 1999, el de la aparición de informaciones sobre la contaminación de la carne y otros derivados de los pollos procedentes de determinadas granjas de Bélgica, que habían sido alimentados con piensos adulterados con grasas de origen industrial que contenían dioxinas. 


\section{REFERENCIAS}

ADAMS, Bill. Sustainable Development and the Greening of Development Theory, en: Schuurman, Frans J. (eds.). Beyond the Impasse. New Directions in Development Theory. Londres: Zed Books, 1993.

BECK, Ulrich. Risk Society, Londres: Sage Publications, 1992a.

BECK, Ulrich. From Industrial Society to the Risk Society: Questions of Survival, Social Structure and Ecological Enlightenment, en: Theory, Culture and Society, v. 9, 1992b.

BODIGUEL, M.; BULLER, H. L'agriculture et l'environnement en Europe: au délà de la Communaute économique, en: Ecodecisión, n. 1, p. 55-59, 1991.

BOWLER, I. R.; BRYANDT, C. R.; NELLIS, M. D. (eds.). Contemporary rural systems in transition, v. 1, Agriculture and Environment, Londres: CAB Int., p. 100-116.

BRENTON, T. The greening of Machiavelli. The evolution of International Environmental Politics, Londres: Earthscan Pub. Ltd., 1994.

CASTELLÓ MUÑOZ, Enrique. El papel del crédito en el desarrollo agrario. Confederación Española de Cajas de Ahorros, Publicaciones del Fondo para la Investigación Económica y Social de la Confederación Española de Cajas de Ahorros, Madrid, 1970.

CLARKE, Simon. The Crisis of Fordism or The Crisis of Social Democracy?, Telos, n. 83, 1990.

ENTRENA DURÁN, Francisco. Cambios en la concepción y en la organización del espacio rural, Revista de Estudios Regionales, n. 34, Málaga, 1992.

ENTRENA DURÁN, Francisco. Cambios en la Construcción Social de lo Rural. De la autarquía a la globalización, Madrid: Tecnos, 1998.

ETXEZARRETA, Miren; VILADOMIÚ, Lourdes. El avance hacia la internacionalización: crónica de una década de la agricultura española, en: Gómez Benito, Cristóbal; González Rodríguez, Juan Jesús (edit.) Agricultura y sociedad en la España contemporánea. Madrid: Ministerio de Agricultura, Pesca y Alimentación/Centro de Investigaciones Sociológicas (CIS), 1997.

GARRIDO, Fernando. La política agroambiental europea: una primera valoración de su aplicación en España, ponencia presentada al VI Congreso Español de Sociología, A Coruña, 24 al 26 de septiembre de 1998.
GARRIDO, Fernando. Análisis de los discursos, actitudes y estrategias de los agricultores y sus organizaciones profesionales ante la introducción de métodos de agricultura sostenible en la agricultura europea, Tesis Doctoral (inédita), presentada en la Escuela Técnica superior de Ingenieros Agrónomos y de Montes, Universidad de Córdoba (España), 1999.

GIDDENS, Anthony. The Consequences of Modernity, Cambridge: Polity Press, 1990.

GINER, Salvador; TÁBARA, David. Piedad Cósmica y Racionalidad Ecológica, en: Revista Internacional de Sociología, n. 19 y 20, p. 41-67, 1998.

GÓMEZ BENITO, Cristóbal. Políticos, burócratas y expertos. Un estudio de la política agraria y la sociología rural en España (1936-1959), Madrid: Siglo XXI editores, 1995.

ILBERY, B. State-assisted farm diversification in the United Kingdom, en: Inglehart, Roland, 1991. El cambio cultural en las sociedades industriales avanzadas, Madrid: CIS/Siglo XXI editores, 1992.

IZCARA PALACIOS, Simón Pedro. El deficit de implementación de las directivas medioambientales de la Unión Europea, en: Revista Internacional de Sociología, n. 24, p. 95-119, 1999.

LORING MIRÓ, Jaime. Crisis de la agricultura capitalista y crisis del capitalismo, Revista de Fomento Social, $\mathrm{n}^{\circ} 187$, Córdoba: ETEA, 1992

MARX, Carlos. El Capital. Madrid: Siglo XXI editores, 1975.

MOYANO, Eduardo; PANIAGUA, Ángel. Agricultura, espacios rurales y medio ambiente, en: Revista Internacional de Sociología, n. 19 y 20, p. 127-152, 1998.

NISBET, Robert. Social Change and History, Nueva York: Oxford Universiy Press, 1969.

PANIAGUA, Angel. Significación social e implicaciones para la política agraria de la "cuestión ambiental" en el medio rural español, en: Gómez Benito y González Rodríguez (eds.). Agricultura y Sociedad en la España Contemporánea, Madrid: Ministerio de Agricultura, Pesca y Alimentación/Centro de Investigaciones Sociológicas (CIS), 1997.

PÉREZ ADÁN, José. En busca de un paradigma económico para la redefinición del concepto de desarrollo sostenible, ponencia presentada al XIII Congreso Mundial de Sociología, Julio, Bielefeld, Alemania, 1994. 
SEVILLA-GUZMÁN, Eduardo. La evolución del campesinado en España. Elementos para una sociología política del campesinado. Barcelona: Península, 1979.

SEVILLA-GUZMÁN, Eduardo; LÓPEZ CALVO, Araceli. Agroecología y campesinado: reflexiones teóricas sobre las ciencias agrarias ante la crisis ecológica, ponencia presentada a las Jornadas de Historia Agraria, Abril, 1993, Almería.

SZTOMPKA, PIOTR. Sociología del cambio social, Madrid: Alianza Editorial, 1995.
UE. El futuro del mundo rural. 1988.

WALLERSTEIN, Inmanuel. Unthinking Social Science, Cambridge: University Press, 1991.

WEBER, Max. Economía y sociedad., México: F.C.E., 1979.

WHITBY, M. (ed.). The European Environment and CAP Reform: Policies and Prospects for Conservation, U.K.: CAB International, 1996. 